
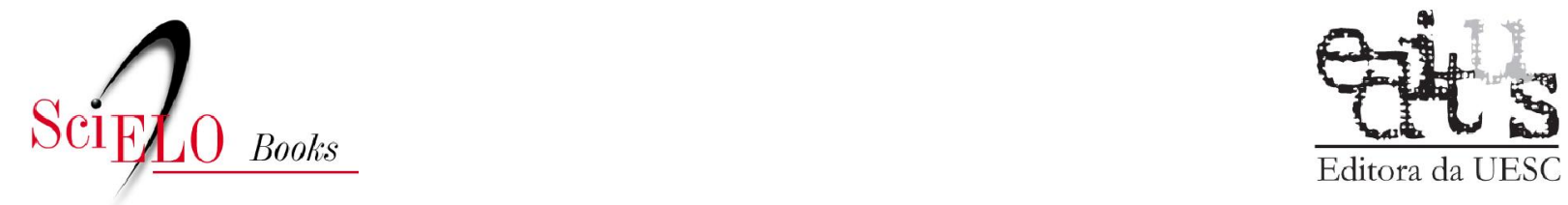

Editora da UESC

\title{
11 - Diversidade genética e fenotípica no gênero Ectatomma
}

\author{
C. Poteaux \\ F. C. Prada-Achiardi \\ F. Fernández \\ J. -P. Lachaud
}

POTEAUX, C., et al. Diversidade genética e fenotípica no gênero Ectatomma. In: DELABIE, JHC., et al., orgs. As formigas poneromorfas do Brasil [online]. Ilhéus, BA: Editus, 2015, pp. 127-144.

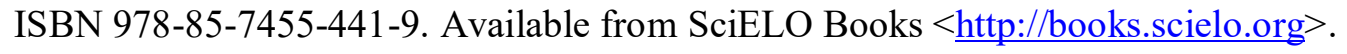

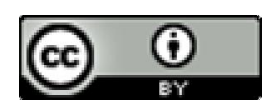

All the contents of this work, except where otherwise noted, is licensed under a Creative Commons Attribution $\underline{4.0 \text { International license. }}$

Todo o conteúdo deste trabalho, exceto quando houver ressalva, é publicado sob a licença Creative Commons Atribição 4.0.

Todo el contenido de esta obra, excepto donde se indique lo contrario, está bajo licencia de la licencia Creative Commons Reconocimento 4.0. 


\title{
Diversidade genética
} e fenotípica no gênero Ectatomma

\author{
C. Poteaux, F. C. Prada-Achiardi, F. Fernández, J. -P. Lachaud
}

\section{Resumo}

O gênero de formigas Ectatomma (Ectatomminae) está atualmente situado no clado Formicoide. Este gênero possui 15 espécies reconhecidas e inclui formigas relativamente grandes e endêmicas da Região Neotropical. Estas espécies são relativamente comuns em diversas áreas (habitats como florestas secas, florestas úmidas e savanas) abaixo de $1500 \mathrm{~m}$ de altitude. A maioria dessas formigas é predadora generalista, mas também podem se alimentar de polpa de frutas, mel e néctar. A ampla variação de seu desempenho ambiental, estratégias de forrageio e dieta justificam a sua abundância na Região Neotropical. A primeira revisão do gênero foi realizada por William Brown Jr. em 1958, que enfrentou dificuldades em delimitar algumas espécies de Ectatomma. Alguns destes problemas foram parcialmente resolvidos por Kugler; Brown, que sugeriram algumas sinonímias e reconheceram 12 espécies. Arias-Penna redescreveu E. confine; Almeida descreveu duas espécies do Brasil, E. vizottoi e E. suzanae. Feitosa et al. descreveram E. parasiticum, a primeira Ectatomma parasita social, originária do México. Embora existam atualmente 15 espécies de Ectatomma descritas, estudos recentes mostraram que esta diversidade é subestimada devido a espécies crípticas ou amostragem insuficiente. Neste capítulo, sintetizamos da literatura e de nossa própria experiência dados de variação fenotípica a partir de características morfológicas, ecológicas, características de vida e genéticas (citogenética e estrutura populacional). A variação morfológica foi registrada em E. tuberculatum, E. goninion e E. ruidum ao longo de sua distribuição geográfica. Porém, assim como em outras formigas, este tipo de variação foi a principal fonte de inflação taxonômica, com muitos nomes desnecessários propostos anteriormente na história do gênero. $\mathrm{O}$ desafio neste táxon é encontrar uma delimitação correta das espécies, usando várias fontes de dados como morfologia, química, genética e biologia (e.g. comportamento de nidificação). A existência de espécies crípticas em E. tuberculatum e E. ruidum, por exemplo, foi recentemente observada a partir de um estudo de filogenia molecular. A variação fenotípica também pode ser expressa baseada em alterações comportamentais ou em características da história de vida das espécies. Decidimos apresentar apenas algumas características comuns, ou por outro lado, específicas de algumas espécies de Ectatomma como a arquitetura de ninho, distribuição de ninhos e organização social. Os ninhos de todas as espécies do gênero Ectatomma

POTEAUX, C.; PRADA-ACHIARDI, F. C.; FERNÁNDEZ, F.; LACHAUD, J. -P. Diversidade genética e fenotípica no gênero Ectatomma. In: DELABIE, Jacques H. C. et al. As formigas poneromorfas do Brasil. Ilhéus: Editus, 2015. p. 127-144. 
são terrícolas, mesmo aqueles de espécies que demonstram hábitos arborícolas como $E$. tuberculatum. Geralmente os ninhos apresentam o mesmo padrão: uma arquitetura simples com um único orifício de entrada e uma abertura direta na superfície do solo, conduzindo a uma galeria que se aprofunda conectando-se a consecutivas câmaras (de quatro a 12, de acordo com a espécie) variando de 0.68 a $3.60 \mathrm{~m}$, de acordo com a espécie. A estrutura dos ninhos parece variar dependendo do ambiente e provavelmente da estação. No entanto, a variação também pode ocorrer de acordo com o tamanho da colônia (ou estado de desenvolvimento) e estrutura do solo. O padrão de distribuição de ninhos também parece variar de acordo com a espécie (sobreposição, distribuição aleatória, padrão agregado, distribuição em manchas). Além disso, a polidomia, que é a formação de ninhos múltiplos e separados que permitem intercâmbio entre eles, de operárias e da prole ocorre em E. tuberculatum e foi sugerida para E. brunneum e E. opaciventre. A organização social foi estudada em diferentes espécies de Ectatomma e colônias poligínicas foram identificadas em sete das 15 espécies (E. ruidum, E. tuberculatum, E. parasiticum, E. brunneum, E. permagnum, E. planidens (referida como E. edentatum), e E. vizottoi). Entretanto, dados baseados em marcadores genéticos usados para investigar em detalhes a estrutura sociogenética das colônias foram realizados apenas com E. tuberculatum e $E$. ruidum, as quais desenvolvemos loci microssatélites específicos. Embora Ectatomma seja um gênero muito difundido e comum na Região Neotropical, sua taxonomia é pouco conhecida, com várias questões não respondidas, como a delimitação de algumas espécies ou complexos de espécies crípticas (como em E. tuberculatum e E. ruidum), a interpretação da variação intra $v s$ interespecífica (como em E. goninion), o problema da parafilia (como no par E. tuberculatum / E. parasiticum) e também o status de espécie descrito por Almeida (E. vizottoi e E. suzanae). Esperamos que estudos em andamento, incluindo a filogenia molecular do gênero, possam elucidar a delimitação de espécies, biogeografia e evolução de algumas características biológicas como microginia, parasitismo e preferência de habitats.

\section{Abstract}

Abstract - Phenotypic and genetic diversity in Ectatomma - Ectatomma is a genus of ants belonging to Ectatomminae, currently located in the Formicoid group. With 15 recognized species, the genus includes relatively large ants endemic to the Neotropical Region. These species are relatively common in diverse areas such as wet forest, savannah, and dry forest habitats below $1500 \mathrm{~m}$ in altitude. Most of them are generalist predators but they also consume fruit pulp, honey and plant nectars. The wide variation in their environmental performance, foraging strategies and dietexplainstheir abundance in the Neotropics. The first review of this genus was done by William Brown Jr. in 1958, who recognized the difficulties in delimiting some Ectatomma species. Some of these problems were partly solved by Kugler and Brown, who suggested some synonymies and recognized 12 species. Arias-Penna re-described E. confine; Almeida described two species from Brazil, E. vizotoi and E. suzanae, and Feitosa et al. described the first social parasitic Ectatomma, E. parasiticum from Mexico. While there are currently 15 Ectatomma described species, recent studies have shown that this variability is underestimated due to cryptic species or insufficient sampling. In this chapter, we synthesize from the literature and our own experience data on phenotypic variation, ecological and life traits and genetics. Morphological variation is known for E. tuberculatum, E. goninion and E. ruidum over their geographic distribution. As in other ants, this kind of variation has been the principal source of taxonomic inflation. The challenge with this taxon is to find a correct delimitation of the species, using several sources of data, including morphology, chemistry, genetics and biology. Phenotypic variation can also be expressed by differences in behaviours or life history traits between species, and we here present some features common to or, by contrast, specific to some Ectatomma. The nests of all the species 
of the genus Ectatomma are terricolous, even those of species exhibiting arboricolous habits. Generally, they exhibit the same pattern; a simple architecture with a single entrance hole opening directly on the ground surface and leading to a gallery, which connects with successive chambers (4-12 according to the species) deeper in the ground (0.68-3.60 $\mathrm{m}$ according to the species). The structure of the nests seems to vary depending on the environment and probably with the season, colony size and the structure of the soil. The patterns of nest distribution appear to vary according to the species (overdispersion; random distribution; aggregated pattern; patchy distribution). Polydomy occurs in E. tuberculatum and possibly in E. brunneum and E. opaciventre. Polygynous colonies have been detected in seven of the 15 Ectatomma species (E. ruidum, E. tuberculatum, E. parasiticum, E. brunneum, E. permagnum, E. planidens (referred to as E. edentatum), and E. vizottoi). However, data based on genetic markers to investigate details of the socio-genetic structure of the colonies have only been obtained in E. tuberculatum and E. ruidum, for which we developed specific microsatellite loci. Although Ectatomma is a widespread and common genus in the Neotropics, their taxonomy is surprisingly poorly known, with several issues unanswered, such as: the delimitation of some species or cryptic species complexes (as in $E$. tuberculatum and E. ruidum); the interpretation of infra- $v s$ inter-specific variation (as in $E$. goninion); the problem of paraphyly (as in the E. tuberculatum / E. parasiticum pair); and also the status of species described by Almeida in (E. vizotoi and E. suzanae). Hopefully work in progress, including the molecular phylogeny of the genus, will throw light on species delimitation, biogeography, and evolution of some biological traits such as microgyny and parasitism.

\section{Introdução}

O gênero de formigas Ectatomma, subfamília Ectatomminae, está atualmente situado no clado formicoide (BRADY et al., 2006). Este gênero possui 15 espécies reconhecidas e inclui formigas relativamente grandes e endêmicas da Região Neotropical (KUGLER; BROWN, 1982). Estas espécies são relativamente comuns em diversas áreas (hábitats como florestas secas, florestas úmidas e savanas) abaixo de $1500 \mathrm{~m}$ de altitude (BROWN, 1958). A maioria destas formigas é predadora generalista (BROWN, 1958), mas também se alimentam de mel e néctar. A ampla variação de seu desempenho ambiental, estratégias de forrageio e dieta justificam a sua abundância na Região Neotropical (FERNÁNDEZ, 1991).

A tribo Ectatommini foi criada como um táxon de nível elevado por Emery (1895) e foi colocada como tribo Ectatommini na subfamília Pachycondylinae por Ashmead (1905). A primeira revisão e delimitação da tribo Ectatommini foi realizada por Brown (1958), que a considerou como uma tribo da subfamília Ponerinae e forneceu uma visão geral da fauna global, com chaves para identificação de gêneros e espécies. Lattke (1994) investigou as relações filogenéticas dos caracteres por meio da morfologia e análise cladística, refutando a sugestão feita por Brown (1958) e dividindo Ectatommini em três tribos: Ectatommini (sensu stricto), Paraponerini e Proceratiini. Neste estudo, Lattke (1994) propôs no mínimo seis caracteres derivados para a tribo, incluindo: lamela clipeal anterior, processo prosternal bidentado posteriormente, empódio ausente e ausência do lobo jugal da asa posterior (exceto para Ectatomma). Keller (2000) fez algumas correções na proposta de Lattke, embora a classificação em tribos continue. Nesta reclassificação, Bolton (2003) elevou Ectatommini ao nível de subfamília, incluindo as tribos Ectatommini sensu stricto e Typhlomyrmecini, sugerindo como possível sinapomorfia do grupo a presença de uma crescente fenda na borda convexa inferior do orifício da glândula metapleural. A história taxonômica detalhada da subfamília Ectatomminae é apresentada no capítulo deste livro intitulado "Estado da arte sobre a taxonomia e filogenia da subfamília Ectatomminae", por R. Feitosa; G. Camacho. 
Estudos de filogenia molecular baseados em diferentes sequências genéticas (MOREAU et al., 2006; BRADY et al., 2006; RABELING et al., 2008; SCHMIDT, 2013) apoiam a monofilia das formigas da subfamília Ectatomminae como sugerido por Bolton (2003) e as classificam como um grupo irmão de Heteroponerinae. As duas subfamílias formam um clado próximo a Myrmicinae no clado formicoide (WARD, 2010). A filogenia proposta por Keller (2011), baseada na morfologia dos adultos, também corroborou a monofilia do clado constituído pelas subfamílias Ectatomminae e Heteroponerinae, mas diverge na posição e nas relações dentro de Formicidae, visto que Ectatomminae permaneceu como um grupo irmão de um clado contendo dorilomorfas, Paraponerinae, Agroecomyrmecinae, Myrmicinae e Proceratiinae. No entanto, na filogenia molecular mais recente (MOREAU; BELL, 2013), o clado ectaheteromorfo aparece novamente como um grupo irmão de Myrmicinae.

O gênero Ectatomma foi descrito por F. Smith em 1858, baseado em Formica tuberculata e colocado em Ponerinae pelo mesmo autor, e depois na tribo Poneri (subfamília Ponerinae) por Forel em 1895. Ashmead (1905) criou a tribo Ectatommini para acolher este gênero e Lattke (1994) dividiu a subfamília em duas tribos: a tribo Ectatommini sensu stricto, incluindo Ectatomma, Rhytidoponera e Gnamptogenys e a tribo Typhlomyrmecini. Comparado a esses outros gêneros, Ectatomma mantém muitas plesiomorfias como lamela clipeal provavelmente ausente ou pobremente desenvolvida, uma boa separação dos espiráculos propodeais da face declive do propodeum e a presença de um modesto pedúnculo anterior (pecíolo) (LATTKE, 1994). Este autor também sugeriu a monofilia de Ectatomma devido à presença de tubérculos no pronoto e possivelmente um lóbulo convexo projetando no processo prosternal. Embora existam atualmente 15 espécies de Ectatomma descritas, estudos recentes mostraram que esta diversidade é subestimada devido a espécies crípticas ou amostragem insuficiente (ver a seguir).

\section{Variação fenotípica}

A variação morfológica foi estudada em vários organismos, de plantas (VOLIS et al., 2002) a mamíferos (WAYNE et al., 1991) e/ou até mesmo insetos (MOUSSEAU, 1989; PÉLABON et al., 2010). Quatro tipos de fatores podem contribuir para a variação em uma população: pressões genéticas e ambientais (BULL, 1987), endogamia (FOWLER; WHITLOCK, 1999) e iteroparidade (SCHULTZ, 1989).

A variação genética ocorre devido a diferenças genotípicas entre indivíduos. A variação ambiental é causada pela exposição a diferentes macro ou microambientes, assim como por perturbações estocásticas durante o desenvolvimento que resultam em ruído ambiental (NIJHOUT; DAVIDOWITZ, 2003). Os organismos podem diferir em sua resposta a diferenças genéticas e ambientais, alguns sendo relativamente resistentes e capazes de produzir fenótipos similares durante mudanças genéticas (mutacionais) ou ambientais, outros sendo mais sensíveis, ou até plásticos, em suas respostas (PÉLABON et al., 2010). Esta habilidade corresponde à plasticidade fenotípica que caracteriza a habilidade de um organismo em produzir múltiplos fenótipos (STEARNS, 1989; WINTERHALTER; MOUSSEAU, 2007).

Os fatores genéticos são determinantes para as mudanças evolutivas dirigidas pela seleção natural e a manutenção da variação genética tem sido uma questão central da biologia evolutiva desde Darwin (BULL, 1987). Contudo, a variação devido aos efeitos ambientais também é importante porque pode mudar a capacidade de adaptação de uma população (FOWLER; WHITLOCK, 1999). Neste capítulo apresentamos algumas variações morfológicas encontradas nas espécies do gênero Ectatomma conforme a sua área de distribuição e algumas delas podem gerar futuras descrições de novas espécies.

a) Variação baseada em caracteres morfológicos e taxonomia

O gênero Ectatomma atualmente apresenta 15 espécies: Ectatomma brunneum Smith 1858, E. confine Mayr 1870, E. edentatum Roger 1863, E. gibbum Kugler; Brown 1982, E. goninion Kugler; Brown, 1982, E. lugens Emery 1895, E. muticum Mayr 1870, E. opaciventre Roger 1861, E. parasiticum Feitosa; Fresneau 2008, E. permagnum Forel 1908, E. planidens Borgmeier 1939, E. ruidum Roger 1860, E. suzanae Almeida 1986, E. tuberculatum Olivier 1792 e E. vizottoi Almeida, 1987.

A primeira revisão foi realizada por Brown (1958), que enfrentou dificuldades em delimitar algumas espécies de Ectatomma. Alguns destes problemas foram parcialmente resolvidos por Kugler; 


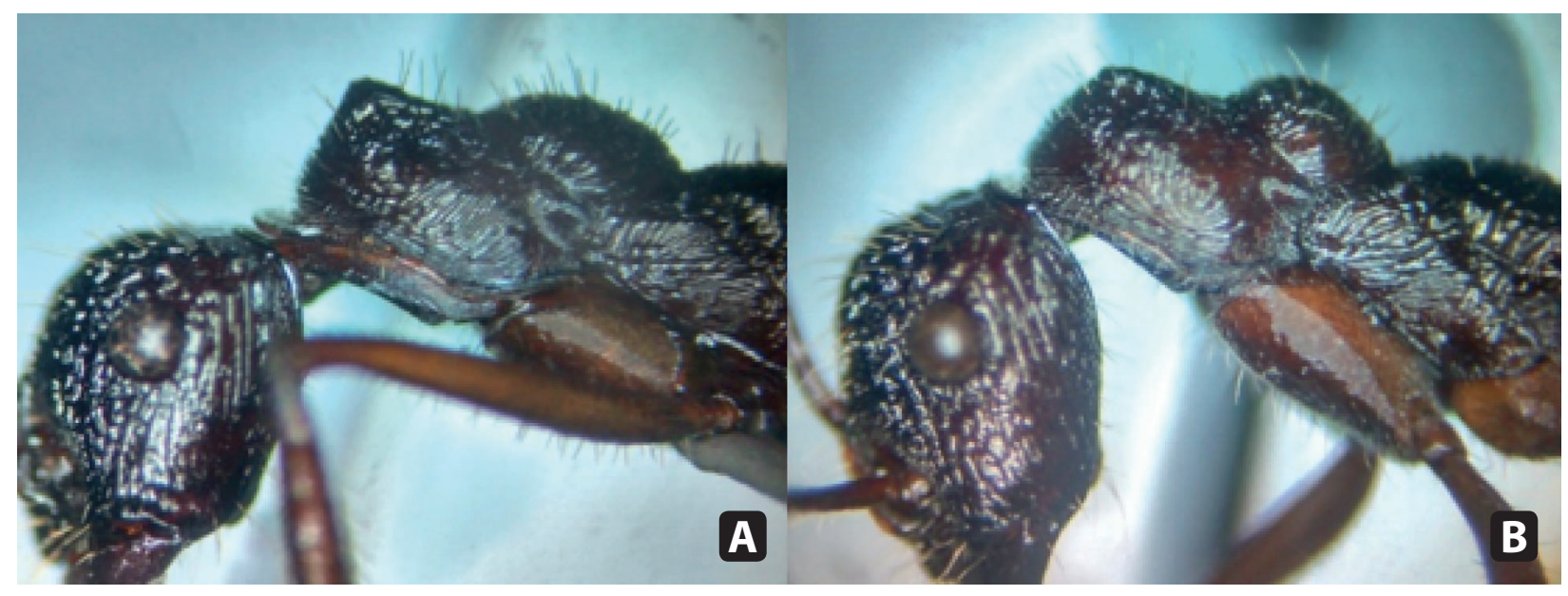

FIGURA 11.2 - Ectatomma goninion. A) populações das Ilhas de Gorgona, Colômbia. B) Populações do Valle del Cauca, Colômbia.

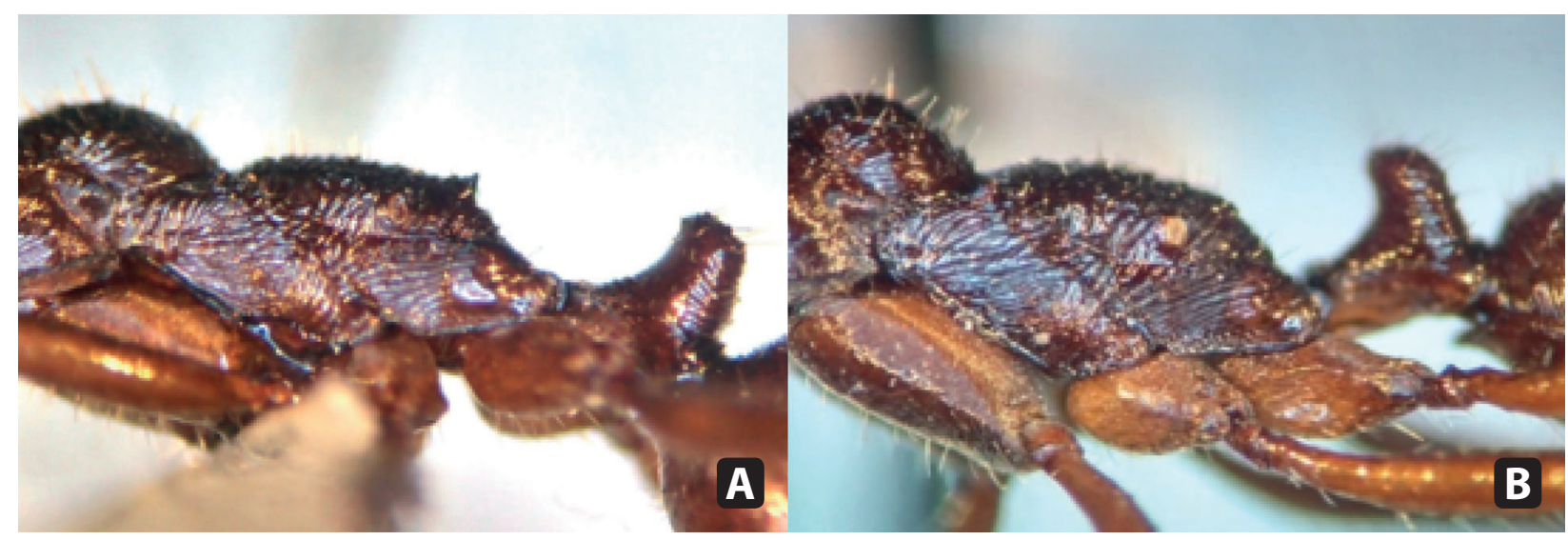

Brown (1982), que sugeriram algumas sinonímias e reconheceram 12 espécies. Arias-Penna (2006) redescreveu E. confine; Almeida $(1986,1987)$ descreveu duas espécies do Brasil: E. vizottoi e E. suzanae. Feitosa et al. (2008) descreveram E. parasiticum, a primeira Ectatomma parasita originária do México.

À primeira vista, a maioria das operárias do gênero Ectatomma pode ser reconhecida pelos tubérculos pronotais e um mesonoto convexo. Os tubérculos pronotais podem ser altamente modificados ou ausentes. Porém, há algumas variações neste caractere, como ocorre em E. goninion na Colômbia: populações das Ilhas de Gorgona exibem a forma típica de E. goninion, com proeminências pronotais bem desenvolvidas e dentes propodeais (Figuras 11.1A e 11.2A), enquanto indivíduos da população continental no Valle del Cauca apresentam ambas as estruturas pronotais e propodeais reduzidas (Figuras 11.1B e 11.2B).
Um caso similar é encontrado em E. tuberculatum, devido a populações na Bahia (Brasil) apresentarem estrias transversais no gáster, enquanto duas populações no México apresentam tipos diferentes de estrias: na população de Tapachula (Estado de Chiapas) possuem estrias concêntricas, enquanto em Apazapan (Estado de Veracruz) exibem estrias em forma de "V". Apesar destas diferenças morfológicas entre as duas populações mexicanas de E. tuberculatum, a espécie é geneticamente homogênea em sua distribuição no México (Figura 11.3).

Assim como em outras formigas, este tipo de variação é a principal fonte de inflação taxonômica, com muitos nomes desnecessários propostos anteriormente na história do gênero. $\mathrm{O}$ desafio neste táxon é encontrar uma delimitação correta das espécies, usando várias fontes de dados como morfologia, química, genética e biologia 
FIGURA 11.3 - Estriação do primeiro segmento do gáster de E. tuberculatum. A) Bahia (Brasil). B) Tapachula (México). C) Apazapan (México).

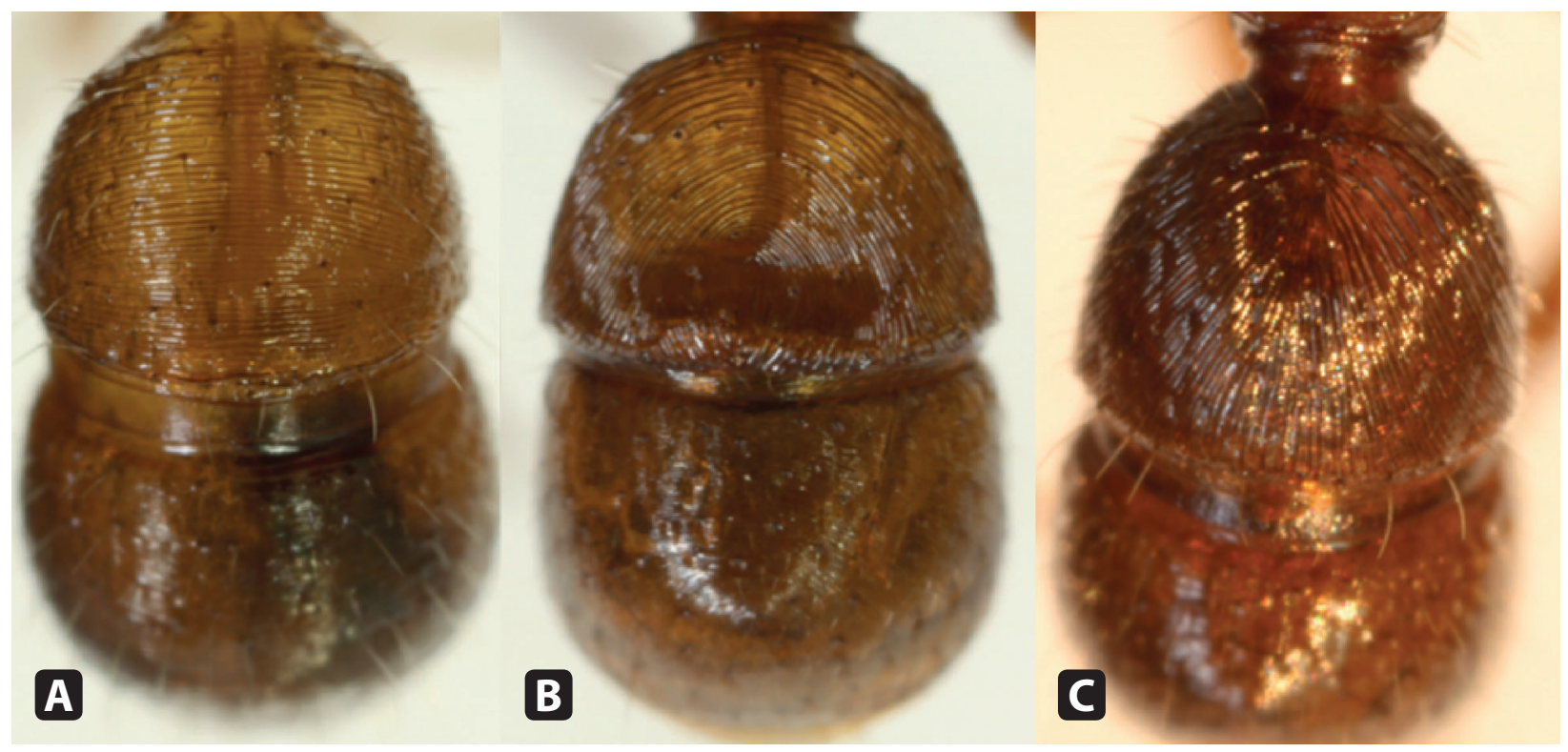

(e.g. comportamento de nidificação). Por outro lado, populações podem conter espécies crípticas: Nettel et al. (submetido) usando filogenia molecular, demonstraram que as populações de E. tuberculatum do Brasil e México pertencem a duas linhagens diferentes, que são divergentes o suficiente para serem consideradas, de fato, duas espécies distintas.

Enquanto a morfologia de E. ruidum aparenta ser relativamente constante em sua distribuição no México, Nettel et al. (submetido) demonstraram que esta espécie também apresenta dois clados que colonizaram a América Central/México independentemente. $\mathrm{O}$ primeiro clado incluiu amostras de uma população do México de E. ruidum, juntamente com amostras da Venezuela, mas sem a presença de microgines (rainha reprodutiva de tamanho reduzido), enquanto que amostras de outra população mexicana com microgines foram agrupadas com amostras do Equador e Panamá. Porém, até o momento, microgines nunca foram relatadas para E. ruidum nestes países (BREED et al., 1990; BREED et al., 1992, 1999; GUÉNARD; McGLYNN, 2013) e são apenas encontradas em populações do México (LACHAUD et al., 1999a, b). Entretanto, Fernández (1991) relatou casos de uma forma ergatoide na Colômbia. No sul do México, estas duas formas de E. ruidum vivem em simpatria em uma planície costeira onde não há nenhuma barreira geográfica notável. Algumas características de vida são comuns em ambas as linhagens de
E. ruidum (e.g. tanatose quando são perturbadas, CUPUL-MAGAÑA, 2009; ataque pela mesma espécie de vespa Eucharitidae, PÉREZ-LACHAUD et al., 2006, LACHAUD; PÉREZ-LACHAUD, dados não publicados). Mas, além da presença ou ausência de microgines, elas também demonstram caracteres biológicos que as distinguem: período de produção de reprodutores (LACHAUD, dados não publicados) e variação dos compostos químicos dos perfis de hidrocarbonetos cuticubres (POTEAUX, dados não publicados). No começo do século 20 , outra espécie (E. aztecum) foi descrita no sudoeste do México (Estado de Michoacán) por Emery (1901). Esta espécie foi revisada por Kugler; Brown (1982) e atualmente é considerada um sinônimo júnior de $E$. ruidum. Porém, a morfologia de ambas as formas de E. ruidum analisadas aqui são distintas da morfologia descrita de E. aztecum. Portanto, as duas linhagens de $E$. ruidum podem representar duas espécies diferentes; uma correspondendo a "verdadeira" $E$. ruidum e a outra a uma espécie nova e não descrita.

O par de espécies E. parasiticum / E. tuberculatum constitui um caso particular de variação morfológica desde que a inusitada $E$. parasiticum foi inicialmente descrita como uma microgine de E. tuberculatum por Hora et al. (2001). No entanto, um estudo comportamental das interações sociais entre rainhas grandes e pequenas, juntamente com operárias da mesma colônia, deixou claro que as rainhas pequenas eram, de fato, parasitas sociais, uma forma inquilina caracterizada por 
tolerância da rainha hospedeira e ausência de produção de operárias (HORA et al., 2009; FÉNÉRON et al., 2013). Este é o primeiro caso de parasitismo social em Ectatomminae e o nome desta nova espécie é derivado de seu comportamento singular (FEITOSA et al., 2008). Além da redução de tamanho, a parasita pode ser distinguida de sua hospedeira por seu pecíolo alargado, escultura esparsa sobre o corpo e redução dos espinhos propodeais, traços característicos da condição parasitária (WILSON, 1984). De um ponto de vista evolutivo, o parasita está muito próximo filogeneticamente ao seu hospedeiro e pode se originar deste por especiação simpátrica (FÉNÉRON et al., 2013; NETTEL et al., submetido), sendo incluído no clado das populações mexicanas de E. tuberculatum.

b) Variação baseada em características de vida e ecológicas

A variação fenotípica também pode ser expressa em alterações comportamentais ou por características de vida entre espécies. Decidimos focar apenas em algumas características como a arquitetura de ninho, distribuição de ninhos e organização social. A dispersão e a estrutura populacional serão abordadas em outro momento.

Os ninhos de Ectatomma e sua distribuição

Os ninhos de todas as espécies do gênero Ectatomma são terrícolas, mesmo os de espécies que demonstram hábitos arborícolas como $E$. tuberculatum. Geralmente os ninhos apresentam uma arquitetura similar simples (ver TSCHINKEL, 2005, 2011; CERQUERA; TSCHINKEL, 2010) ou até mais elaborada (ver BEUGNON et al., 2001; KLINGENBERG et al., 2007) dentre aquelas encontradas em várias outras espécies de formigas, incluindo algumas Formicinae ou Myrmicinae. Contudo, os ninhos são bem menos complexos do que os de muitas outras espécies, até de outras de formigas poneromorfas como Dinoponera quadriceps, Harpegnathos saltator, Pachycondyla senaaraensis, ou Paltothyreus tarsatus (ARAUJO et al., 1990; DÉJEAN et al., 1993; BRAUN et al., 1994; DEJEAN; LACHAUD, 1994; PEETERS et al., 1994). Sua complexidade é definitivamente menor

FIGURA 11.4 - A) Estrutura rígida semelhante a uma chaminé de um ninho de E. ruidum de Tapachula (México) para evitar que entre água em períodos de chuva (altura: de 1,5-2cm); B) Chaminé característica dos ninhos de E. tuberculatum (altura: $35 \mathrm{~cm}$ ).

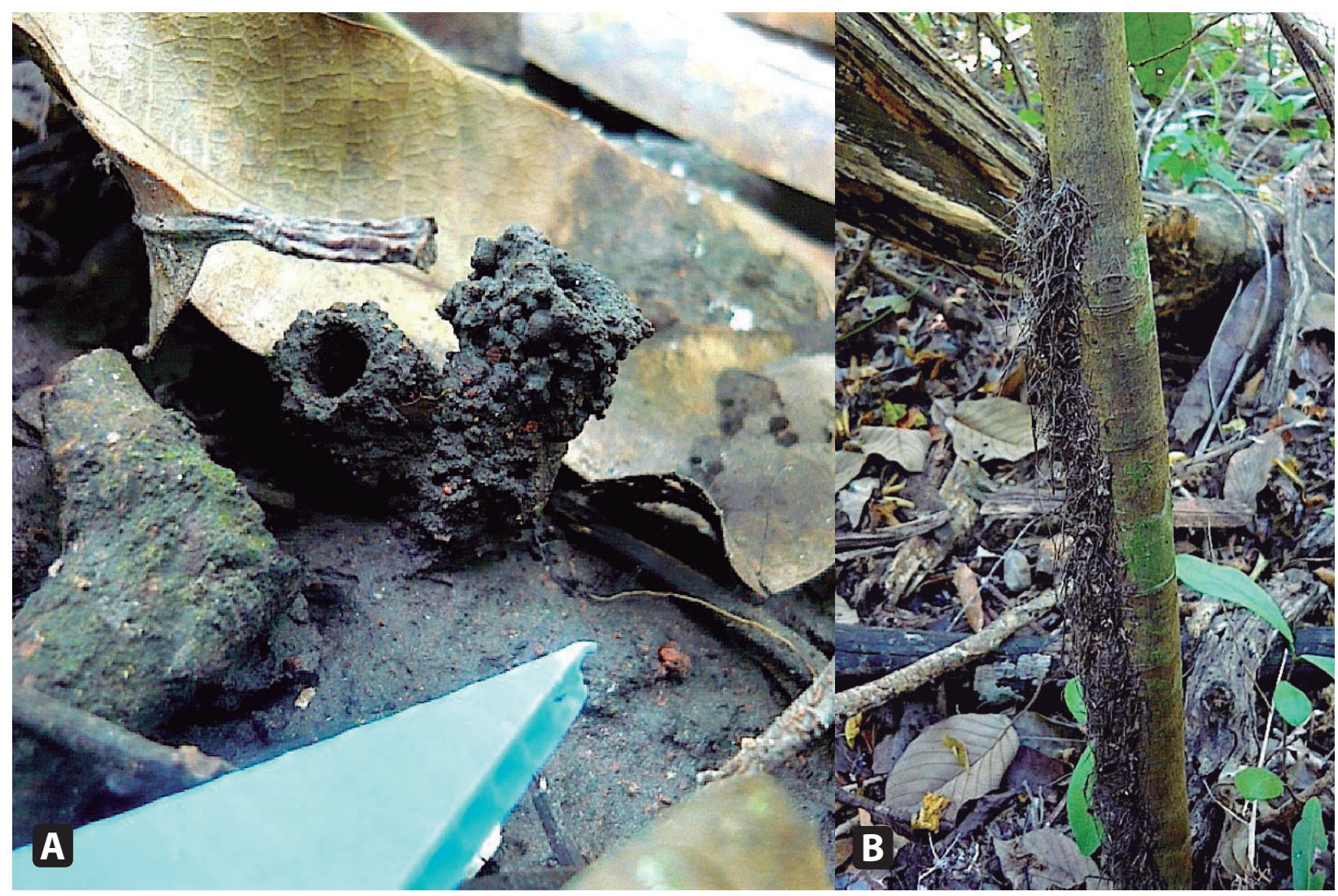


comparada aos ninhos terrícolas de membros de subfamílias mais derivadas como Pogonomyrmex (TSCHINKEL, 2004), Atta (MOSER, 2006; COSARINSKY; ROCES, 2012), Lasius (KHUONG et al., 2011), ou Formica (BRISTOW et al., 1992), ou aos ninhos arborícolas de Azteca (MAYER; VOGLMAYR, 2009), Dolichoderus (ROHE; MASCHWITZ, 2003) ou Polyrhachis (ROBSON; KOHOUT, 2005).

Tipicamente, o único orifício de entrada é uma abertura direta na superfície do solo, eventualmente circundada por uma depressão térrea rasa que pode aumentar gradativamente. Em apenas algumas espécies como E. opaciventre (ANTONIALLI-JUNIOR; GIANNOTTI, 1997), ou de acordo com características particulares do hábitat ou em condições climáticas como em E. brunneum (VIEIRA; ANTONIALLI-JUNIOR, 2006) e E. ruidum (LACHAUD, dados não publicados), uma estrutura rígida semelhante a uma chaminé, feita de solo compactado e em algumas ocasióes entrelaçada com palha seca (Figura 11.4A), pode ser construída como proteção, essencialmente para evitar que entre água em períodos de chuva (ver LeBRUN et al., 2011). Porém, a estrutura mais complexa acima do orifício de entrada encontrada no gênero Ectatomma, é obviamente, a chaminé ca- racterística dos ninhos de E. tuberculatum (Figura 11.4B), construída na base de árvores ou arbustos (COOK, 1905; WHEELER, 1924). Uma galeria tubular de aproximadamente $3 \mathrm{~cm}$ de diâmetro e feita de feltro entrelaçado e detritos vegetais fibrosos misturados com terra, estende-se em linha reta na base da árvore a uma altura de aproximadamente $30 \mathrm{~cm}$, mas em algumas ocasiões pode alcançar até $110 \mathrm{~cm}$ (PÉREZ-LACHAUD et al., 2010).

Em todas as espécies de Ectatomma, uma galeria com aproximadamente o mesmo diâmetro do orifício de entrada é construída abaixo da entrada, em posição vertical ou levemente inclinada e conecta-se a câmaras gradativamente mais profundas de formas relativamente ovais. A estrutura dos ninhos parece variar dependendo do ambiente, provavelmente da estação e, para algumas espécies, no entanto, a variação também pode ocorrer de acordo com o tamanho da colônia (ou estágio de desenvolvimento) e, também, com a estrutura do solo (WEBER, 1946; PÉREZLACHAUD et al., 2011). Independentemente destes fatores, o número máximo de câmaras encontrado em colônias maduras varia de acordo com a espécie em questão, de um máximo de quatro câmaras em E. permagnum (PAIVA; BRANDÃO, 1989) e E. planidens (ANTONIALLI-JUNIOR;

FIGURA 11.5 - Perfil esquemático de quatro ninhos simples de Ectatomma vizottoi (conforme VIEIRA et al., 2007) com câmaras adicionais relativamente profundas (A, B e C)
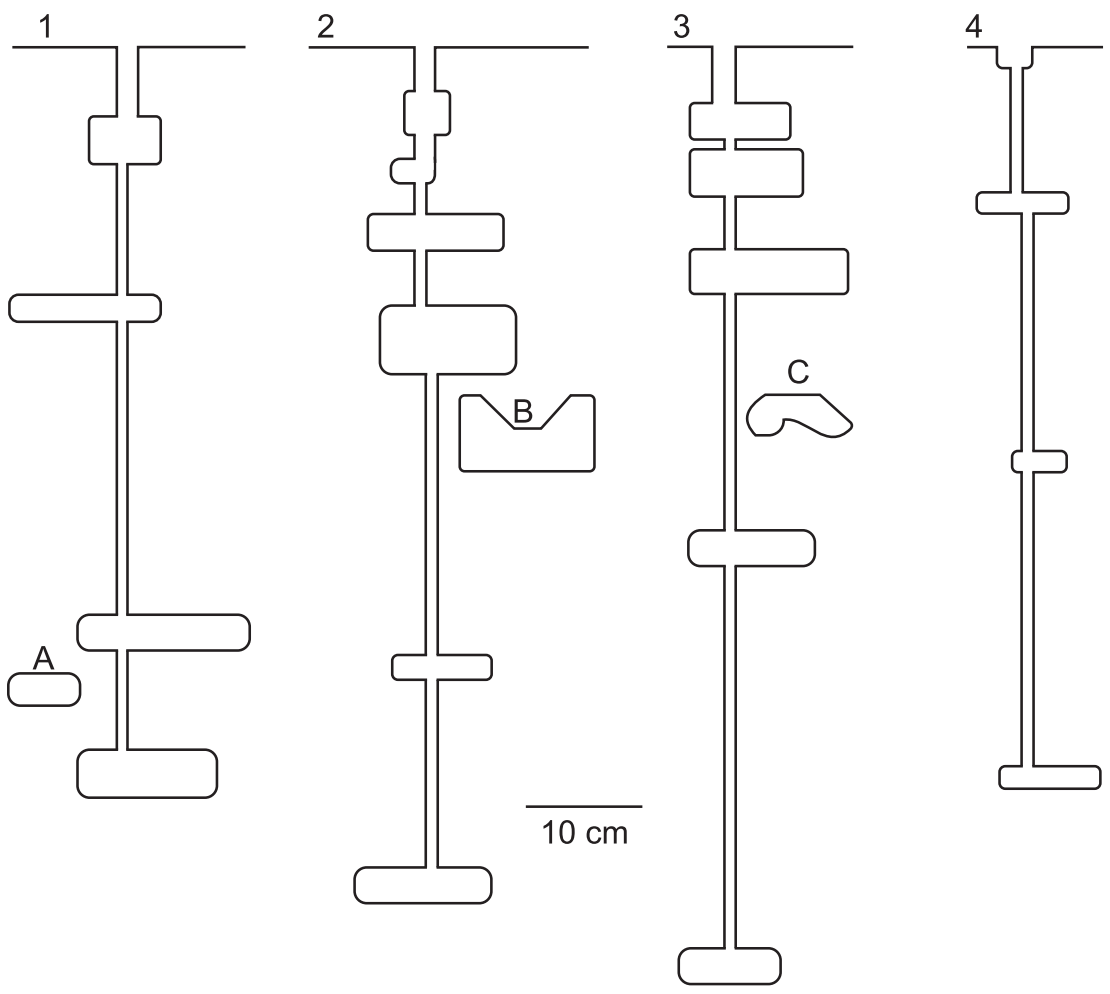
GIANNOTTI, 2001, 2002, 2003) a 10 câmaras em E. vizottoi (VIEIRA et al., 2007; e.g. Figura 11.5) e E. tuberculatum (LACHAUD, dados não publicados) e até mesmo 12 câmaras em E. ruidum (LACHAUD, dados não publicados). De forma semelhante, a profundidade máxima da câmara mais profunda em colônias maduras pode variar de $0.68 \mathrm{~m}$ em E. opaciventre (ANTONIALLI-JUNIOR; GIANNOTTI, 1997) até $2 \mathrm{~m}$ em E. tuberculatum (VALENZUELA-GONZÁLEZ et al., 1995) e E. ruidum (LACHAUD, dados não publicados), e até mesmo $3.60 \mathrm{~m}$ em E. vizottoi (VIEIRA et al., 2007). O tamanho da colônia também varia muito de acordo com a estação, maturidade da colônia e entre as espécies. Sem contar as fundações jovens com menos de seis operárias, o número médio de adultos (rainhas, gines alados, machos e operárias) por colônia é inferior a $50 \mathrm{em} E$. opaciventre, $E$. permagnum e E. planidens, entre 80 e 120 em E. ruidum, E. brunneum e E. vizottoi, considerando a hipótese improvável de que cada ninho é independente, superior a $490 \mathrm{em}$ E. tuberculatum.

Os padrões de distribuição de ninhos foram pouco investigados na maioria das espécies de Ectatomma, com exceção de E. ruidum e E. tuberculatum, mas parecem variar de acordo com a espécie: sobreposição em E. ruidum, independentemente da densidade de populações (LEVINGS; FRANKS, 1982; BREED et al., 1990; SCHATZ; LACHAUD, 2008), mas algumas vezes aleatória (MEDINA, 1994) ou até mesmo um padrão agregado em alguns hábitats (SANTAMARÍA, et al., 2009); sobreposição em E. opaciventre (PIE, 2004); distribuição aleatória em E. brunneum (RENARD et al., dados não publicados, citados por SCHATZ; LACHAUD, 2008) e E. permagnum (PAIVA; BRANDÃO, 1989); distribuição em manchas associada a presença de plantas que dão suporte a estrutura dos ninhos em E. tuberculatum (WHEELER, 1986; MAJER et al., 1994; MEDEIROS et al., 1995; SCHATZ; LACHAUD, 2008). Esta distribuição em manchas, combinada com a ausência de rainhas em muitas colônias amostradas, dão indícios à polidomia (formação de ninhos múltiplos espacialmente isolados que podem trocar operárias e a prole) (DEBOUT et al., 2007). A polidomia é sugerida em outras espécies como E. brunneum (LAPOLA et al., 2003; VIEIRA; ANTONIALLIJUNIOR, 2006), e E. opaciventre (TOFOLO et al., 2014), mesmo que a presença da rainha em menos de $20 \%$ dos ninhos coletados tenha sido resultado de uma escavação incompleta devido a estrutura do solo que não permitiu que as câmaras mais profundas fossem encontradas em ambas as espécies, mas comprovada apenas em E. tuberculatum (ZINCK et al., 2007, 2008). Detalharemos mais precisamente a dispersão de E. tuberculatum e $E$. ruidum em sua área de distribuição abaixo.

\section{Organização social e poliginia}

A organização social foi estudada em diferentes espécies de Ectatomma e as colônias poligínicas foram encontradas na maioria das espécies: E. ruidum, E. tuberculatum, e E. parasiticum (ver abaixo), mas também E. brunneum apresentou duas das 12 colônias avaliadas ocorrendo uma rainha e duas fêmeas ápteras (LACHAUD; PÉREZ-LACHAUD, dados não publicados), E. permagnum com cinco das 10 colônias contendo de duas a cinco fêmeas ápteras e quase todas fecundadas (PAIVA; BRANDÃO, 1989), E. planidens (referida como E. edentatum) com três das cinco colônias contendo de duas a quatro fêmeas ápteras, com apenas uma funcional em cada caso (ANTONIALLI-JUNIOR; GIANNOTTI, 2002), e E. vizottoi com cinco das seis colônias contendo de três a 10 fêmeas ápteras, porém, aparentemente, apresentando monoginia funcional (VIEIRA et al., 2007, 2012). Entretanto, dados baseados em marcadores genéticos usados para investigar em detalhes a estrutura sociogenética das colônias foram obtidos apenas em E. tuberculatum e E. ruidum, para as quais desenvolvemos loci microssatélites específicos (POTEAUX et al., 2003; LENOIR et al., 2011).

A espécie inquilina E. parasiticum constitui um caso especial de espécie poligínica, uma vez que produz machos e apenas fêmeas sexuadas. Por exemplo, em 13 das 15 colônias (com uma rainha cada) coletadas em Apazapan (Estado de Veracruz), encontramos de duas a 18 fêmeas ápteras (HORA et al., 2001). A poliginia em $E$. tuberculatum, originalmente descrita por Cook (1905), foi recentemente confirmada, no Brasil, como sendo facultativa, secundária e funcional e em média, com quatro rainhas fecundadas por colônia (HORA et al., 2005b) e um parentesco médio de 0.3 entre operárias companheiras de ninho (ZINCK et al., 2007). Além disso, nem a poliandria ou mesmo o desvio reprodutivo entre as rainhas foram encontrados nesta espécie. Embora o desvio reprodutivo entre as rainhas seja frequentemente encontrado em colônias poligínicas (BOURKE; FRANKS, 1995), Zinck et al. (2007) relataram que 
todas as rainhas de E. tuberculatum, de fato, contribuem igualmente na produção de operárias. Isto corrobora as observações comportamentais, demonstrando que todas as rainhas depositavam ovos e que não havia hierarquia de dominância ou comportamento agonístico aparente nestas colônias poligínicas brasileiras (HORA et al., 2005b).

Porém, colônias de E. tuberculatum são monogínicas em diferentes lugares no México. Apenas $1 \%$ de poliginia foi relatada para as 253 colônias coletadas na região de Soconusco durante 25 anos (PÉREZ-LACHAUD et al., 2010, 2011), incluindo apenas duas rainhas; e sua parasita social nunca foi encontrada, exceto em Apazapan, onde E. parasiticum foi descoberta (FÉNÉRON et al., 2013). De fato, em Apazapan, quase todas as rainhas em colônias poligínicas de E. tuberculatum são reprodutoras efetivas (HORA et al., 2007) e têm taxas de postura de ovos similares, sem uma hierarquia de dominância óbvia ou interações agressivas (HORA et al., 2001, 2005a). Todavia, ocorre um canibalismo de ovos entre rainhas ( $1 / 4$ dos ovos colocados por rainhas foram roubados por uma companheira de ninho e apenas ovos frescos foram destruídos, geralmente durante a fase de oviposição) (HORA et al., 2005a; HORA et al., 2007). O canibalismo de ovos ocorreu em aproximadamente metade das colônias estudadas (6/14 das colônias estudadas), mas foi distribuído igualmente entre as rainhas. Como consequência, a divisão reprodutiva entre as rainhas foi desigual, resultando em desvio reprodutivo na produção de operárias (HORA et al., 2007). Este comportamento pode ser resultado de um conflito reprodutivo, competição por recursos nutritivos ou pode ter ocorrido como forma de limitar a produção da prole, com estas hipóteses não sendo mutuamente exclusivas. Assim, investigações comportamentais e genéticas adicionais são necessárias para desvendar estas duas hipóteses diferentes.

Em colônias de E. ruidum, a presença de várias fêmeas fecundadas e ápteras é frequente e ocorre entre aproximadamente 20 e $40 \%$ das colônias em algumas populações (LACHAUD et al., $1999 a$ ), até $83 \%$ em outras (LACHAUD et al., dados não publicados). Nesta espécie existe um polimorfismo evidente dentro da casta das rainhas, com macro e microgines coincidindo na mesma população, e na maioria das vezes, dentro da mesma colônia (LACHAUD et al., 1999b; LENOIR et al., 2011). Embora as colônias poligínicas incluam, em média, três rainhas fecundadas (LACHAUD et al., 1999a), as evidências indicam que apenas uma rainha por colônia aparenta ser funcionalmente reprodutiva de modo fisiológico (CADENA et al., 2001) e genético (LENOIR et al., 2011), conduzindo, desta maneira, a uma monoginia funcional. $\mathrm{Na}$ maioria dos casos, uma macrogine foi a reprodutora efetiva e outras macrogines e microgines foram apenas reprodutoras excedentes, talvez produzidas como garantia de sobrevivência (CHÉRON et al., 2009). Contudo, em alguns casos, microgines são definitivamente capazes de realizar fundação haplometrótica (LACHAUD et al., 1999b; LENOIR et al., 2011) mesmo se o crescimento da colônia é claramente mais lento do que com macrogines como demonstrado em fundações em laboratório (SCHATZ et al., 1996). Devido a interações agressivas não terem sido relatadas entre rainhas companheiras de ninho, assim como entre rainhas estranhas introduzidas em fundações pleometróticas em laboratório (CADENA et al., 2001), podemos supor que uma inibição feromonal é produzida pela rainha mais fértil, que consequentemente monopoliza a reprodução (HOLMAN et al., 2010).

É provável que ocorra um fenômeno possivelmente semelhante em E. planidens (referida como E. edentatum), por causa do relato de dois casos de rainhas menores (ANTONIALLI-JUNIOR; GIANNOTTI, 2001) e poderiam corresponder a microgines, mas tal informação precisaria ser confirmada.

\section{Variação genética}

\section{a) Citogenética}

Uma vez que os cromossomos constituem o suporte físico do DNA e podem ser o tema de rearranjos e alterações, a citogenética é uma ferramenta útil para a compreensão biológica da história de uma espécie, especialmente para a taxonomia e estudos do mecanismo de especiação. Os parâmetros geralmente utilizados em estudos citogenéticos são o número de cromossomos, a sua morfologia e estrutura em segundo plano e protocolos de bandeamento para demonstrar os rearranjos cromossômicos.

Barros et al. (2008) realizaram um estudo citogenético de cinco espécies do gênero Ectatomma em populações dos estados brasileiros da Bahia e de Minas Gerais. Neste gênero, o número cromossômico é geralmente alto, 
e nos casos analisados, variou de $2 \mathrm{n}=20$ a 46 : E. brunneum, $2 \mathrm{n}=44$ (fórmula cariotípica: $2 \mathrm{~K}$ $=22 \mathrm{M}+22 \mathrm{~A}) ;$ E. muticum, $\mathrm{n}=20(\mathrm{~K}=16 \mathrm{M}+$ $4 \mathrm{~A})$; E. permagnum, $2 \mathrm{n}=46(2 \mathrm{~K}=20 \mathrm{M}+26 \mathrm{~A})$; E. tuberculatum, $2 \mathrm{n}=36(2 \mathrm{~K}=30 \mathrm{M}+6 \mathrm{~A}), E$. edentatum, $2 \mathrm{n}=46$ ( sem informação da fórmula cariotípica).

Se substituirmos estes resultados da citogenética na árvore em Nettel et al. (submetido), podemos notar que as espécies E. brunneum e E. permagnum são próximas, pertencem ao mesmo clado e também apresentam fórmulas cariotípicas mais próximas, enquanto E. tuberculatum pertence a um clado diferente. No entanto, Ectatomma muticum, caracterizada pela fórmula cariotípica com o maior número de cromossomos metacêntricos juntamente com E. edentatum, se encontram em uma posição basal na árvore. Estes resultados corroboram a Teoria da Interação Mínima proposta por Imai et al. (1994), modelo que prevê um aumento no número de cromossomos acrocêntricos devido à fissão cêntrica. Portanto, ao longo da evolução, os cromossomos tendem a aumentar em número e diminuir em tamanho, mesmo se existir uma evidência recente de que fusões em mudanças de cromossomos podem ter um papel importante na redução do número de cromossomos em Formicidae (CARDOSO et al., 2014).

Infelizmente, nenhuma variação cromossômica entre as populações de um único táxon foi investigada no estudo de Barros et al. (2008); portanto, a comparação dos dois tipos de resultados é muito limitada. Um esforço em investigar tal diversidade deve ocorrer no futuro para se entender melhor o padrão de distribuição e evolução das espécies de Ectatomma.

\section{b) Dispersão e estrutura populacional}

Estratégias alternativas de reprodução como a poliginia e a microginia podem ser explicadas pela diminuição do sucesso na dispersão e fundações solitárias por rainhas em habitats nos quais se acredita que as condições ambientais tornem este tipo de fundação custosa (HEINZE; TSUJI, 1995). A distribuição espacial e temporal de habitats e a disponibilidade de locais de nidificação parecem estar entre os fatores-chave que determinam o sucesso de estratégias reprodutivas (HEINZE; TSUJI, 1995; McGLYNN, 2010). As limitações ambientais são frequentemente difíceis de medir, mas os registros tendem a mostrar uma influência da variação ecológica no fenótipo da colônia (CLÉMENCET et al., 2005; McGLYNN, 2010; STEINER et al., 2010).

No mosaico de formigas arbóreas nos habitats da Região Neotropical, espécies de formigas dominantes e mutuamente exclusivas ocupam territórios diferentes e a sua distribuição de ninhos é agregada espacialmente em manchas, influenciando, desta maneira, os padrões da estrutura genética populacional. No Brasil, Zinck et al. (2007) investigaram a estrutura genética populacional de E. tuberculatum no mosaico de agrossistemas de cacau da Bahia. Suas análises revelaram uma forte estrutura genética tanto em escalas espaciais pequenas quanto em grandes. Neste caso, o padrão de isolamento por distância encontrado em uma determinada mancha pôde ser explicado pela dispersão limitada de fêmeas devido à fundação de colônias dependentes, i.e. porque as rainhas fundaram colônias com a ajuda de operárias perto de seus ninhos de origem (PAMILO, 1991; BOURKE; FRANKS, 1995). Por outro lado, a ausência de endogamia em E. tuberculatum sugere que a dispersão de machos não é tão restrita quanto a dispersão de fêmeas. Além disso, os registros genéticos e resultados de experimentos comportamentais em campo (ZINCK et al., 2008) tendem a confirmar a polidomia nesta espécie, algo sugerido anteriormente por diferentes autores (GARCÍA-PÉREZ et al., 1991; HORA et al., 2005a) e ninhos que possam permanecer interligados após fissão, por meio do intercâmbio de operárias como em outras espécies (CHAPUISAT et al., 1997; PEDERSEN; BOOMSMA, 1999). Em conclusão, para as espécies brasileiras, a combinação de diferentes características biológicas como a poliginia secundária, a reprodução por fissão e polidomia contribui para a manutenção de sua dominância ecológica no mosaico de formigas arbóreas.

No México, apenas uma população de E. tuberculatum com colônias poligínicas foi encontrada até agora, em Apazapan (Veracruz), onde também ocorre a espécie parasita (HORA et al., 2001; FÉNÉRON et al., 2013). De acordo com um estudo feito por Wheeler (1986) no Panamá e com nossas observações pessoais em Apazapan, as colônias provavelmente têm múltiplas entradas no ninho e são polidômicas como no Brasil. Uma espécie parasita poderia originar diretamente da espécie hospedeira se as características de vida como poliginia, polidomia e endogamia fossem 
agrupadas (BUSCHINGER, 1990) e um possível caminho evolutivo neste caso seria a especiação simpátrica causada pelo isolamento reprodutivo entre o hospedeiro e o parasita (BUSCHINGER, 1990, 2009; SAVOLAINEN; VEPSÄLÄINEN, 2003; VEPSÄLÄINEN et al., 2009). A hipótese parcimoniosa aqui é a evolução simpátrica de $E$. parasiticum a partir de E. tuberculatum, como os sequenciamentos moleculares tendem a mostrar (FÉNÉRON et al., 2013; NETTEL et al., submetido). De acordo com a sua distribuição muito limitada, podemos inferir que a dispersão de E. parasiticum é muito restrita e que parasita colônias de E. tuberculatum provenientes de uma mancha.

Colônias com microgines de E. ruidum, por outro lado, são sobrepostas e essencialmente monodômicas (BREED et al., 1990; SCHATZ et al., 1998; SCHATZ; LACHAUD, 2008). A fundação de novas colônias em E. ruidum não é realizada por fissão ou fundação dependente, mas é conhecida por ser haplometrótica (independente), não claustral (LACHAUD; FRESNEAU, 1987) e por ocorrer após o voo nupcial (LACHAUD; PÉREZ -LACHAUD, dados não publicados). Porém, em Tapachula (Estado de Chiapas), onde duas das populações com microgines estão localizadas, $E$. ruidum apresenta uma densidade de ninhos muito alta, de 5.900 a 11.200 ninhos/ha (SCHATZ; LACHAUD, 2008), o que promoveu alta competição intraespecífica. Ambos os locais de coleta estão localizados em áreas cultivadas (plantações de cacau e café) onde as práticas humanas poderiam ter gerado uma densidade exagerada de colônias. Nestas condições, os riscos de dispersão tornam a fundação solitária custosa para esta espécie porque locais para novas nidificações estão indisponíveis. Como sugerido em estudos com outras espécies de formigas poligínicas (PAMILO, 1991; SUNDSTRÖM, 1995; HEINZE, 2008; McGLYNN, 2010), a disponibilidade para nidificação é um fator-chave que favorece a filopatria entre as fêmeas reprodutivas, com a adoção de rainhas que acasalaram recentemente em sua colônia de origem ou em uma vizinha. Este padrão de adoção e a dispersão limitada foram confirmados por análises genéticas (LENOIR et al., 2011). Produzir e/ou adotar rainhas com tamanho reduzido é então um benefício para sua colônia de origem, uma vez que seu custo de produção é reduzido para a colônia comparado ao custo de produção de rainhas grandes.
Ao contrário da maioria das espécies de formigas onde a proximidade social é bem desenvolvida e causa de forte competição intraespecífica, o nível de tolerância entre as colônias de Ectatomma da mesma população é incrivelmente alto. A consequência desta alta tolerância mediada pela alta densidade populacional consiste na sobreposição de territórios de colônias e a demonstração de cleptobiose intraespecífica, como relatado em E. ruidum (BREED et al., 1990, DE CARLI et al., 1998) e observada uma vez em E. tuberculatum (LACHAUD, dados não publicados). Contudo, o reconhecimento social é sempre possível e testes anteriores demonstraram que quanto maior a distância entre as populações, mais intensas são as relações agonísticas entre as não companheiras de ninho (BREED et al., 1992). Além disso, a poliginia poderia impactar a homogeneidade entre as operárias dentro da colônia e na escala populacional e, portanto, no nível de tolerância entre colônias vizinhas e colônias estranhas.

\section{Conclusão}

Embora Ectatomma seja um gênero muito difundido e comum na Região Neotropical, sua taxonomia é pouco conhecida, com várias questões não respondidas, como, por exemplo, a delimitação de algumas espécies ou complexos de espécies crípticas (como em E. tuberculatum e E. ruidum), a interpretação da variação intra $v s$ interespecífica (como em E. goninion), o problema da parafilia (como no par E. tuberculatum / E. parasiticum) e também o status de espécie descrito por Almeida (E. vizottoi e E. suzanae). Esperamos que trabalhos em andamento, incluindo a filogenia molecular do gênero, possam elucidar a delimitação de espécies, biogeografia e evolução de algumas características biológicas como microginia, parasitismo e preferência de hábitats.

\section{Agradecimentos}

Somos gratos a Luan Dias Lima para a tradução do texto em Português, a William Antonialli Jr para uma releitura final e a Jonathan Majer por corrigir o abstrato. Este estudo é fruto de um projeto de colaboração (F. Fernandez e C. Poteaux) para estudar formigas do gênero Ectatomma e recebeu financiamento do projeto C12A01 da Chamada Ecos Nord-Colciencias, assim que do Programa PRONEX CNPq/FAPESB, projeto PNX 011/2009. 


\section{Referências}

ALMEIDA, A. J. Descrição de quatro machos do gênero Ectatomma Smith, 1858 (Hymenoptera, Formicidae, Ponerinae). Quid, Teresina, v. 6, p. 24-38, 1986 (página 27, macho descrito).

ALMEIDA, A. J. Descrição de seis fêmeas do gênero Ectatomma Smith, 1858 (Hymenoptera, Formicidae, Ponerinae). Anais Sociedade Nordestina Zoologia, v. 1, p. $175-183,1987$.

ANTONIALLI-JUNIOR, W. F.; GIANNOTTI, E. Nest architecture and population dynamics of the Ponerinae ant, Ectatomma opaciventre Roger (Hymenoptera: Formicidae). Journal of Advanced Zoology, v. 18, n. 2, p. 64-71, 1997.

ANTONIALLI-JUNIOR, W. F.; GIANNOTTI, E. Nest architecture and population dynamics of the ponerine ant Ectatomma edentatum (Hymenoptera, Formicidae). Sociobiology, v. 38, n. 3, p. 475-486, 2001.

ANTONIALLI-JUNIOR, W. F.; GIANNOTTI, E. Division of labor in Ectatomma edentatum (Hymenoptera, Formicidae). Sociobiology, v. 39, n. 1, p. 37-63, 2002.

ANTONIALLI-JUNIOR, W. F.; GIANNOTTI, E. Temporal polyethism in workers of Ectatomma edentatum (Formicidae: Ponerinae). Sociobiology, v. 41, n. 2, p. 461-478, 2003.

ARAUJO, C. Z. D. ; LACHAUD, J. -P.; FRESNEAU, D. Le système reproductif chez une ponérine sans reine: Dinoponera quadriceps Santschi. Behavioural Processes, v. 22, n. 1, p. 101-111, 1990.

ARIAS-PENNA, T. M. Redescription of the ant Ectatomma confine Mayr, 1870 (Hymenoptera: Formicidae) and first record for Colombia. Entomological News, v. 117, n. 4, p. 445-450, 2006.

ASHMEAD, W. H. A skeleton of a new arrangement of the families, subfamilies, tribes and genera of the ants, or the superfamily Formicoidea. The Canadian Entomologist, v. 37, n. 11, p. 381-384, 1905.

BARROS, L. A. C. et al. Cytogenetic studies of the Neotropical ant genus Ectatomma (Formicidae: Ectatomminae: Ectatommini). Sociobiology, v. 51, n. 3, p. 555-561, 2008.

BEUGNON, G.; CHAGNÉ, P.; DEJEAN, A. Colony structure and foraging behavior in the tropical formicine ant, Gigantiops destructor. Insectes Sociaux, v. 48, n. 4, p. 347-351, 2001.
BOLTON, B. Synopsis and classification of Formicidae. Gainesville: Memoires of the American Entomological Institute, v. 71.p. 370, 2003.

BOURKE, A. F. G.; FRANKS, N. R. Social evolution in ants. Princeton: Princeton University Press. 1995. p. 550.

BRADY, S. G. et al. Evaluating alternative hypotheses for the early evolution and diversification of ants. Proceedings of the National Academy of Sciences of the United States of America, v. 103, n. 48, p. 18172-18177, 2006.

BRAUN, U.; PEETERS, C.; HÖLLDOBLER, B. The giant nests of the African stink ant Paltothyreus tarsatus (Formicidae, Ponerinae). Biotropica, v. 26, n. 3, p. 308-3011, 1994.

BREED, M. D. et al. Thievery, home ranges, and nestmate recognition in Ectatomma ruidum. Oecologia, v. 84, n. 1, p. 117-121, 1990.

BREED, M. D. et al. Acquired chemical camouflage in a tropical ant. Animal Behaviour, v. 44, n. 3, p. 519-523, 1992.

BREED, M. D. et al. Thief workers and variation in nestmate recognition behavior in a ponerine ant, Ectatomma ruidum. Insectes Sociaux, v. 46, n. 4, p. 327-331, 1999.

BRISTOW, C. M. et al. Nest structure and colony cycle of the Allegheny mound ant, Formica exsectoides Forel (Hymenoptera: Formicidae). Insectes Sociaux, v. 39, n. 4, p. 385-402, 1992.

BROWN, W. L. JR. Contributions toward a reclassification of the Formicidae. II. Tribe Ectatommini (Hymenoptera). Bulletin of the Museum of Comparative Zoology, v. 118, p. 173-362, 1958.

(Página 208, sinonímia senior de concolor).

BULL, J. J. Evolution of phenotypic variance. Evolution, v. 41, n. 2, p. 303-315, 1987.

BUSCHINGER, A. Sympatric speciation and radiative evolution of socially parasitic ants - Heretic hypotheses and their factual background. Journal of Zoological Systematics and Evolutionary Research, v. 28, n. 4, p. 241-260, 1990.

BUSCHINGER, A. Social parasitism among ants: a review (Hymenoptera: Formicidae). Myrmecological News, v. 12, p. 219-235, 2009.

CADENA, A. et al. Inhibition de la ponte dans les sociétés polygynes de Ectatomma ruidum (Hymenoptera, Formicidae, Ponerinae). Actes des Colloques Insectes Sociaux, v. 14, p. 87-93, 2001. 
CARDOSO, D. C. et al. The role of fusion in ant chromosome evolution: insights from cytogenetic analysis using a molecular phylogenetic approach in the genus Mycetophylax. PLoS One, v. 9, n. 1, p. e87473, 2014.

CERQUERA, L. M.; TSCHINKEL, W. R. The nest architecture of the ant Odontomachus brunneus. Journal of Insect Science, v. 10, n. 64, p. 1-12, 2010.

CHAPUISAT, M.; GOUDET, J.; KELLER, L. Microsatellites reveal high population viscosity and limited dispersal in the ant Formica paralugubris. Evolution, v. 51, n. 2, p. 475-482, 1997.

CHÉRON, B. et al. Queen replacement in the monogynous ant Aphaenogaster senilis: supernumerary queens as life insurance. Animal Behaviour, v. 78, n. 6, p. 1317-1325, 2009.

CLÉMENCET, J.; VIGINIER, B.; DOUMS, C. Hierarchical analysis of population genetic structure in the monogynous ant Cataglyphis cursor using microsatellite and mitochondrial DNA markers. Molecular Ecology, v. 14, n. 2, p. 3735-3744, 2005.

COOK, O. F. The social organization and breeding habits of the cotton-protecting Kelep of Guatemala. United States Department of Agriculture, Technical Series, v. 10, p. 1-55, 1905.

COSARINSKY, M. I.; ROCES, F. The construction of turrets for nest ventilation in the grass-cutting ant Atta vollenweideri: import and assembly of building materials. Journal of Insect Behavior, v. 25, n. 3, p. 222-241, 2012

CUPUL-MAGAÑA, F. G. Primera observación del comportamiento defensivo por muerte simulada de la hormiga Ectatomma ruidum (Roger, 1861) (Formicidae, Ponerinae). Acta Zoológica Mexicana, v. 25, n. 1, p. 199-201, 2009.

DE CARLI, P. et al. Études en milieu naturel du comportement de cleptobiose chez la fourmi néotropicale Ectatomma ruidum (Hymenoptera, Ponerinae). Actes des Colloques Insectes sociaux, v. 11, p. 29-32, 1998.

DEBOUT, G. et al. Polydomy in ants: what we know, what we think we know, and what remains to be done. Biological Journal of the Linnean Society, v. 90, n. 2, p. 319-348, 2007.

DEJEAN, A.; BEUGNON, G.; LACHAUD, J. -P. Spatial components of foraging behavior in an African ponerine ant, Paltothyreus tarsatus. Journal of Insect Behavior, v. 6, n. 3, p. 271-285, 1993.
DEJEAN, A.; LACHAUD, J. -P. Ecology and behavior of the seed-eating ponerine ant Brachyponera senaarensis (Mayr). Insectes Sociaux, v. 41, n. 2, p. 191 210, 1994.

EMERY, C. Di Gattung Dorylus Fab. und die systematische Eintheilung der Formiciden.

Zoologische Jahrbücher, Abteilung für Systematik, Geographie und Biologie der Tiere, v. 8, p. 685-779, 1895.

EMERY, C. Notes sur les sous-familles des dorylines et ponérines (Famille des Formicides). Annales de la Société Entomologique Belge, v. 45, p. 32-54, 1901.

FEITOSA, R. M. et al. A new social parasite in the ant genus Ectatomma F. Smith (Hymenoptera, Formicidae, Ectatomminae). Zootaxa, v. 1713, p. 47-52, 2008.

FÉNÉRON, R. et al. Discrimination of the social parasite Ectatomma parasiticum by its host sibling species (E. tuberculatum). Psyche: A Journal of Entomology, v. 2013, p. 1-11, 2013.

FERNÁNDEZ F. Las hormigas cazadoras del género Ectatomma (Formicidae: Ponerinae) en Colombia. Caldasia, v. 16, n. 79, p. 551-564, 1991.

FOREL, A. A fauna das formigas do Brasil. Boletim do Museu Paraense de História Natural, Belém, v. 1, n. 2, p. 89-143, 1895.

FOWLER, K.; WHITLOCK, M. C. The distribution of phenotypic variance with inbreeding. Evolution, v. 53, n. 4, p. 1143-1156, 1999.

GARCÍA-PÉREZ, J. A. et al. Rutas de forrajeo utilizadas por Ectatomma tuberculatum $\mathrm{O}$.

(Hymenoptera, Ponerinae) en una plantación de cacao en el Soconusco, Chiapas, México. Folia Entomológica Mexicana, v. 82, p. 161-171, 1991.

GUÉNARD, B.; McGLYNN, T. P. Intraspecific thievery in the ant Ectatomma ruidum is mediated by food availability. Biotropica, v. 45, n. 4, p. 497-502, 2013.

HEINZE, J. The demise of the standard ant (Hymenoptera: Formicidae). Myrmecological News, v. 11, p. 9-20, 2008.

HEINZE, J.; TSUJI, K. Ant reproductive strategies. Researches on Population Ecology, v. 37, n. 2, p. 135149, 1995.

HOLMAN, L. et al. Identification of an ant queen pheromone regulating worker sterility. Proceeding of the Royal Society of London B, v. 277, p. 3793-3800, 2010 . 
HORA, R. R. et al. Queen-size dimorphism in the ant Ectatomma tuberculatum (Hymenoptera: Formicidae: Ponerinae). Sociobiology, v. 38, n. 3, p. 407-420, 2001.

HORA, R. R. et al. Small queens in the ant Ectatomma tuberculatum: a new case of social parasitism.

Behavioral Ecology and Sociobiology, v. 59, n. 2, p. 285-292, 2005a.

HORA, R. R. et al. Facultative polygyny in Ectatomma tuberculatum (Formicidæ, Ectatomminæ). Insectes Sociaux, v. 52, n. 2, p. 194-200, 2005b.

HORA, R. R. et al. Egg cannibalism in a facultative polygynous ant: conflict for reproduction or strategy to survive? Ethology, v. 113, n. 9, p. 909-916, 2007.

HORA, R. R. et al. Social interactions between an inquiline ant, Ectatomma parasiticum, and its host, Ectatomma tuberculatum (Formicidae, Ectatomminae). Journal of Ethology, v. 27, n. 2, p. 285-288, 2009.

IMAI, H. T. ; TAYLOR, R. W. ; CROZIER, R. H. Experimental bases for the minimum interaction theory. I. Chromosome evolution in ants of the Myrmecia pilosula species complex (Hymenoptera: Formicidae: Myrmeciinae). Japanese Journal of Genetics, v. 69, n. 2, p. 137-182, 1994.

KELLER, R. A. Cladistics of the tribe Ectatommini (Hymenoptera: Formicidae): A reappraisal. Insect Systematics; Evolution, v. 31, n. 1, p. 59-69, 2000.

KELLER, R. A. A phylogenetic analysis of ant morphology (Hymenoptera: Formicidae) with special reference to the poneromorph subfamilies. Bulletin of the American Museum of Natural History, v. 355, p. $1-90,2011$.

KHUONG, A. et al. A computational model of ant nest morphogenesis. In: LENAERTS, T. et al. (Org.): Advances in Artificial Life, ECAL 2011, Proceedings of the Eleventh European Conference on the Synthesis and Simulation of Living Systems. Resumos... The MIT Press, 2011.p. 404-411.

KLINGENBERG, C.; BRANDÃO, C. R. F.; ENGELS, W. Primitive nest architecture and small monogynous colonies in basal Attini inhabiting sandy beaches in southern Brazil. Studies on Neotropical Fauna and Environment, v. 42, n. 2, p. 121-126 2007.

KUGLER, C.; BROWN JR, W. L. Revisionary and other studies on the ant genus Ectatomma, including the descriptions of two new species. Search: Agriculture (Cornell), n. 24, p. 1-8, 1982.
LACHAUD, J. -P.; FRESNEAU, D. Social regulation in primitive ants. In: DENEUBOURG, J. -L.; PASTEELS, J. M. (Org.). From Individual Characteristics to Collective Organisation: the example of Social Insects. Basel: Birkhäuser Verlag, 1987.p. 177-196.

LACHAUD, J. -P. et al. Polygynie et stratégies reproductrices chez une ponérine néotropicale, Ectatomma ruidum. Actes des Colloques Insectes Sociaux, v. 12, p. 53-59, 1999a.

LACHAUD, J. -P. et al. Queen dimorphism and reproductive capacity in the ponerine ant, Ectatomma ruidum Roger. Oecologia, v. 120, n. 4, p. 515-523, 1999 b.

LAPOLA, D. M.; ANTONIALLI-JUNIOR, W. F.; GIANNOTTI, E. Arquitetura de ninho da formiga neotropical Ectatomma brunneum F. Smith, 1858 (Formicidae: Ponerinae) em ambientes alterados. Revista Brasileira de Zoociências, Juiz de Fora, v. 5, n. 2, p. 177-188, 2003.

LATTKE, J. E. Phylogenetic relationships and classifications of Ectatommine ants (Hymenoptera: Formicidae). Entomologica Scandinavica, v. 25, n. 1, p. 105-119, 1994

LeBRUN, E. G. ; MOFETT, M. ; HOLWAY, D. A. Convergent evolution of levee building behavior among distantly related ant species in a floodplain ant assemblage. Insectes Sociaux, v. 58, n. 2, p. 263-269, 2011.

LENOIR, J. -C. et al. The role of microgynes in the reproductive strategy of the neotropical ant Ectatomma ruidum. Naturwissenschaften, v. 98, n. 4, p. 347-356, 2011.

LEVINGS, S. C.; FRANKS, N. R. Patterns of nest dispersion in a tropical ground ant community. Ecology, v. 63, n. 2, p. 338-344, 1982.

MAJER, J. D. ; DELABIE, J. H. C.; SMITH, M. R. B. Arboreal ant community patterns in Brazilian cocoa farms. Biotropica, v. 26, n. 1, p. 73-83, 1994.

MAYER, V. E.; VOGLMAYR, H. Mycelial carton galleries of Azteca brevis (Formicidae) as a multispecies network. Proceedings of the Royal Society B, v. 276 , n. 1671 , p. 3265-3273, 2009.

McGLYNN, T. P. Polygyny in thief ants responds to competition and nest limitation but not food resources. Insectes Sociaux, v. 57, n. 1, p. 23-28, 2010.

MEDEIROS, M. A.; FOWLER, H. G.; BUENO, O. C. Ant (Hym., Formicidae) mosaic stability in Bahian cocoa plantations: implications for management. Journal of Applied Entomology, v. 119, n. 1-5, p. 411-414, 1995. 
MEDINA, C. A. Nidificacion y patrones de distribucion espacial de nidos de hormigas en una sabana tropical, Carimagua: llanos orientales de Colombia. Boletín del Museo de Entomología de la Universidad del Valle, v. 2, n. 1,2, p. 31-42, 1994.

MOREAU, C. S. et al. Phylogeny of the ants: diversification in the age of angiosperms. Science, v. 312, n. 5770, p. 101-104, 2006.

MOREAU, C. S.; BELL, C. D. Testing the museum versus cradle tropical biological diversity hypothesis: phylogeny, diversification, and ancestral biogeographic range evolution of the ants. Evolution, v. 67, n. 8, p. 2240-2257, 2013.

MOSER, J. C. Complete excavation and mapping of a Texas leafcutting ant nest. Annals of the Entomological Society of America, v. 99, n. 5, p. 891897, 2006.

MOUSSEAU, T. A.; ROFF, D. A. Adaptation to seasonality in a cricket: patterns of phenotypic and genotypic variation in body size and diapause expression along a cline in season length. Evolution, v. 43, n. 7, p. 1483-1496, 1989.

NIJHOUT, H. F.; DAVIDOWITZ, G. Developmental perspectives on phenotypic variation, canalization, and fluctuating asymmetry. In: POLAK, M. (Org.). Developmental stability: causes and consequences. Oxford: Oxford University Press, Oxford, 2003. p. 3-13.

PAIVA, R. V. S.; BRANDÃO, C. R. F. Estudos sobre a organização social de Ectatomma permagnum Forel, 1908 (Hymenoptera: Formicidae). Revista Brasileira de Biologia, v. 49, n. 3, p. 783-792, 1989.

PAMILO, P. Evolution of colony characteristics in social insects. 2. Number of reproductive individuals. The American Naturalist, v. 138, n. 2, p. 412-433, 1991.

PEDERSEN, J. S.; BOOMSMA, J. J. Genetic analysis of colony structure in polydomous and polygynous ant populations. Biological Journal of the Linnean Society, v. 66, n. 1, p. 115-144, 1999.

PEETERS, C. et al. "Wall-papering" and elaborate nest architecture in the ponerine ant Harpegnathos saltator. Insectes Sociaux, v. 41, n. 2, p. 211-218, 1994.

PÉLABON, C. et al. Evolution of variation and variability under fluctuating, stabilizing, and disruptive selection. Evolution, v. 64, n. 7, p. 19121925, 2010.
PÉREZ-LACHAUD, G. et al. Biology and behavior of Kapala (Hymenoptera: Eucharitidae) attacking Ectatomma, Gnamptogenys, and Pachycondyla (Formicidae: Ectatomminae and Ponerinae) in Chiapas, Mexico. Annals of the Entomological Society of America, v. 99, n. 3, p. 567-576, 2006.

PÉREZ -LACHAUD, G. et al. High prevalence but relatively low impact of two eucharitid parasitoids attacking the Neotropical ant Ectatomma tuberculatum (Olivier). Biological Control, v. 52, n. 2, p. 131-139, 2010.

PÉREZ-LACHAUD, G.; VALENZUELA, J. E. ; LACHAUD, J. -P. Is increased resistance to parasitism at the origin of polygyny in a Mexican population of the ant Ectatomma tuberculatum (Hymenoptera: Formicidae)? Florida Entomologist, v. 94, n. 3, p. 677-684, 2011.

PIE, M. R. Foraging ecology and behaviour of the ponerine ant Ectatomma opaciventre Roger in a Brazilian savannah. Journal of Natural History, v. 38, n. 6, p. 717-729, 2004

POTEAUX, C. et al. Isolation of polymorphic microsatellite loci in the ponerine ant Ectatomma tuberculatum. Molecular Ecology Notes, v. 3, n. 4, p. 635-637, 2003.

\section{RABELING, C.; BROWN, J. M.; VERHAAGH, M.}

Newly discovered sister lineage sheds light on early ant evolution. Proceedings of the National Academy of Sciences of the United States of America, v. 105, n. 39, p.14913-14917, 2008.

ROBSON, S. K. A.; KOHOUT, R. J. Evolution of nest-weaving behaviour in arboreal nesting ants of the genus Polyrhachis Fr. Smith (Hymenoptera: Formicidae). Australian Journal of Entomology, v. 44, n. 2, p. 164-169, 2005.

ROHE, W.; MASCHWITZ, U. Carton nest building and trophobiont manipulation in the south-east Asian ant Dolichoderus sulcaticeps (Mayr 1870) (Hymenoptera: Formicidae). Journal of Natural History, v. 37, n. 23, p. 2835-2848, 2003.

SANTAMARÍA, C.; ARMBRECH, I.; LACHAUD, J. -P. Nest distribution and food preferences of Ectatomma ruidum (Hymenoptera: Formicidae) in shaded and open cattle pastures of Colombia. Sociobiology, v. 53, n. 2B, p. 517-541, 2009.

SAVOLAINEN, R.; VEPSÄLÄINEN, K. Sympatric speciation through intraspecific social parasitism. Proceedings of the National Academy of Sciences of the United States of America, v. 100, n. 12, p. 7169 $7174,2003$. 
SCHATZ, B. et al. Existence de microgynes chez la fourmi ponérine Ectatomma ruidum Roger. Actes des Colloques Insectes Sociaux, v. 10, p. 169-173, 1996.

SCHATZ, B. et al. Densité et distribution des nids chez la fourmi Ectatomma ruidum Roger (Hymenoptera; Formicidae). Actes des Colloques Insectes sociaux, v. 11, p. 19-28, 1998.

SCHATZ, B.; LACHAUD, J. -P. Effect of high nest density on spatial relationships in two dominant ectatommine ants (Hymenoptera: Formicidae).

Sociobiology, v. 51, n. 3, p. 623-643, 2008.

SCHMIDT, C. Molecular phylogenetics of ponerine ants (Hymenoptera: Formicidae: Ponerinae). Zootaxa, v. 3647, n 2, p. 201-250, 2013.

SCHULTZ, D. L. The evolution of phenotypic variance with iteroparity. Evolution, v. 43, n.2, p. 473$475,1989$.

SMITH, F. Catalogue of hymenopterous insects in the collection of the British Museum, Part VI. Formicidae. London: Taylor and Francis. 1858. 280p.

STEARNS, S. C. The evolutionary significance of phenotypic plasticity. Bioscience, v. 39, n. 7, p. 436-445, 1989.

STEINER, F. M.; CROZIER, R. H.; SCHLICKSTEINER, B. C. Colony structure. In: LACH, L.; PARR, C. L.; ABBOTT, K. L. (Org.). Ant Ecology. Oxford: Oxford University Press, 2010. p. 177-193.

SUNDSTRÖM, L. Sex allocation and colony maintenance in monogyne and polygyne colonies of Formica truncorum (Hymenoptera, Formicidae) - The impact of kinship and mating structure. The American Naturalist, v. 146, n. 2, p. 182-201, 1995.

TOFOLO, V. C. et al. Polydomy in the ant Ectatomma opaciventre. Journal of Insect Science, v. 14, n. 21, p. 1-16, 2014.

TSCHINKEL, W. R. The nest architecture of the Florida harvester ant, Pogonomyrmex badius. Journal of Insect Science, v. 4, n. 21, p. 1-19, 2004.

TSCHINKEL, W. R. The nest architecture of the ant, Camponotus socius. Journal of Insect Science, v. 5, n.9, p. 1-18, 2005.

TSCHINKEL, W. R. The nest architecture of three species of north Florida Aphaenogaster ants. Journal of Insect Science, v. 11, n. 105, p. 1-30, 2011.
VALENZUELA-GONZÁLEZ, J.; LÓPEZ-MÉNDEZ, A.; LACHAUD, J. -P. Activity patterns and foraging activity in nests of Ectatomma tuberculatum (Hymenoptera: Formicidae) in cacao plantations. Southwestern Entomologist, v. 20, n. 4, p. 507-515, 1995.

VEPSÄLÄINEN, K. et al. Genetic differentiation between the ant Myrmica rubra and its microgynous social parasite. Insectes Sociaux, v. 56, n. 4, p. 425-437, 2009.

VIEIRA, A. S.; ANTONIALLI-JUNIOR, W. F. Populational fluctuation and nest architecture of Ectatomma brunneum (Hymenoptera, Formicidae) in remaining areas of pasture, Dourados - MS, Brasil. Sociobiology, v. 47, n. 1, p. 275-287, 2006.

VIEIRA, A. S.; ANTONIALI-JUNIOR, W. F., FERNANDES, W. D. Modelo arquitetônico de ninhos da formiga Ectatomma vizottoi Almeida (Hymenoptera, Formicidae). Revista Brasileira de Entomologia, v. 51, n. 4, p. 489-493, 2007.

VIEIRA, A. S.; FERNANDES, W. D.; ANTONIALLIJUNIOR, W. F. Behavioral differentiation and ovarian development of unmated gynes, queens, and workers of Ectatomma vizottoi Almeida 1987 (Formicidae, Ectatomminae). Psyche, v. 2012, p. 1-8, 2012.

VOLIS, S.; MENDLINGER, S.; WARD, D.

Differentiation in populations of Hordeum spontaneum along a gradient of environmental productivity and predictability: life history and local adaptation. Biological Journal of the Linnean Society, v. 77, n. 4, p. 479-490, 2002.

WARD, P. S. Taxonomy, Phylogenetics, and Evolution. In: LACH, L.; PARR, C. L.; ABBOTT, K. L. (Org.). Ant Ecology. Oxford: Oxford University Press, 2010. p. 3-17.

WAYNE, R. K. al. A morphologic and genetic study of the island fox, Urocyon littoralis. Evolution, v. 45, n. 8, p. $1849-1868,1991$.

WEBER, N. A. Two common ponerine ants of possible economic significance, Ectatomma tuberculatum (Olivier) and E. ruidum Roger. Proceedings of the Entomological Society of Washington, v. 48, n. 1, p. 1-16, 1946.

WHEELER, D. E. Ectatomma tuberculatum: foraging biology and association with Crematogaster (Hymenoptera; Formicidae). Annals of the

Entomological Society of America, v. 79, n. 2, p. 300303, 1986. 
WHEELER, W. M. Courtship of the Calobatas.

The Kelep ant and the courtship of its mimic,

Cardiacephala myrmex. Journal of Heredity, v. 15, n.

12, p. 485-495, 1924.

WILSON, E. O. Tropical social parasites in the ant genus Pheidole, with an analysis of the anatomical parasitic syndrome (Hymenoptera: Formicidae).

Insectes Sociaux, v. 31, n. 3, p. 316-334. 1984.

WINTERHALTER, W. E.; MOUSSEAU, T. A. Patterns of phenotypic and genetic variation for the plasticity of diapause incidence. Evolution, v. 61, n. 7, p. 1520-1531, 2007.
ZINCK, L. et al. The role of breeding system on ant ecological dominance: genetic analysis of Ectatomma tuberculatum. Behavioral Ecology, v. 18, n. 4, p. 701$708,2007$.

ZINCK, L. et al. Low intraspecific aggression level in the polydomous and facultative polygynous ant Ectatomma tuberculatum. Entomologia Experimentalis et Applicata, v. 126, n. 3, p. 211-216, 2008. 